Bangladesh Journal of Neuroscience 2014; Vol. 30 (2): 84-89

\title{
Ischaemic Stroke and occult cardiac abnormality-A Transthoracic Echocardiography based study
}

\author{
MD. MAHABUBUL A KHANDKER ${ }^{1}$, MD. HASSANUZZAMAN ${ }^{2}$, KANUJ K. BARMAN $^{3}$, \\ MASIHUZZAMAN SAM ${ }^{4}$, KAYASTHAGIR P.K ${ }^{5}$, TOUHIDUR RAHMAN ${ }^{6}$ MOHITUL ISLAM ${ }^{7}$
}

\begin{abstract}
Summary:
Background: Most of the cases of stroke are of ischemic origin. Various cardiac diseases have been shown to increase risk of stroke. Cerebral embolism derived from a diversity of cardiac disorders is responsible for H"20\% of ischemic stroke. AF is the most powerful and treatable cardiac precursorof stroke. Cardiac abnormalities are important risk factors for stroke. A cardiac source of thromboembolism must be excluded in patients presenting with a definite embolic occlusion of a peripheral artery, or multiple thromboembolic episodes in diverse anatomical regions. These patients should undergo transthoracic echocardiography initially and transoesophageal echo if image quality is unsatisfactory because of obesity, lung disease or chest deformity. Methods: An descriptive and observational study done in Neurology unit, Chittagong Medical College hospital from January 2007 to December 2007.Patients presented primarily as ischemic stroke was examined to find out prevalence of occult cardiac abnormality and to find out the frequency of different type cardiac abnormality in ischemic stroke through echocardiography. Results: A total number of 265 patients were examined. Different types of cardiac findings, the maximum number are LV hypertrophy (23\%) and followed by Diastolic dysfunction (17\%), than multiple vulvular disease (8.5\%). Small number of other abnormality found but no PFO and mitral valve prolapse identified in this study. In under 30yrs age group of cases all the abnormal findings found are valvular abnormality. They are mitral stenosis (2), multiple valvular disease (2) and mitral regurgitation (1). In 30 - 49 yrs age group different abnormal findings, most of which are also valvular lesions including aortic stenosis(2), multiple valvular disease(2) and mitral regurgitation(1). Intracardiac thrombus found in one case.In e"5069 yrs age group of patients, maximum abnormality found is $L V H(7)$ followed by Diastolic dysfunction(4).Maximum abnormality found in e"70 yrs of age group is $L V H(3)$ and next to it is distolic dysfunction(2). Interpretation: Echocardiography may provide important information on the cause of ischemic stroke. Taking into account a low rate of findings with direct impact on evidence-based therapeutic strategies, routine use of echocardiography is not warranted in all patients with stroke. In patients younger than 50 years, echocardiography has higher diagnostic yield and should routinely be performed.
\end{abstract}

Introduction:

Stroke is the third leading cause of death in most western countries. ${ }^{1}$ Stroke can be ischemic (85\%) or hemorrhagic (10\% to $15 \%),{ }^{2,3}$ and ischemic stroke can be classified, according to etiology, ${ }^{4}$ as:
(1) large vessel atherosclerosis, (2) cardioembolic, (3) small vessel atherosclerosis (lacunes), (4) other determined etiology, or (5) undetermined etiology. Embolism accounts for $15 \%$ to $20 \%$ of all strokes. 5 Several heart diseases are potentially embolic, ${ }^{5-7}$

1. Asstt. Prof., Neurology Department, Chittagong Medical College.

2. Associate Prof. \& Head of Neurology Dept., Chittagong Medical College

3. Associate Prof. Department of Neurology, Bangabandhu Sheikh Mujib Medical University.

4. Asstt. Prof., Neurology Department, Chittagong Medical College

5. Asstt. Prof., Neurology Department, Chittagong Medical College

6. Medical officer, Dept. of Medicine Chittagong Medical College

7. Asstt. Prof., Neurology Department, Shaheed Suhrawardy Medical College 
and some indicate anticoagulation as beneficial ${ }^{8-}$ 11 and should therefore be identified. Stroke results from either ischemia, due to arterial occlusion or stenosis, or hemorrhage, due to leakage or rupture of an artery. Various cardiac diseases have been shown to increase risk of stroke. Cerebral embolism derived from a diversity of cardiac disorders is responsible for $20 \%$ of ischemic strokes ${ }^{12,13}$. $60 \%$ of the emboli of left ventricular origin have been associated with acute $\mathrm{MI}^{12}$. Although atrial fibrillation, responsible for $50 \%$ of cardioembolic strokes, ${ }^{11}$ can be diagnosed by an ECG, echocardiography is an important test in the diagnosis of the remaining embolic heart diseases. Prevalence of Patent Foramen Ovale a pooled analysis of autopsy studies yielded an average prevalence of patent foramen ovale (PFO) of $26 \%$ (range $17 \%$ to $35 \%$ ). In most echocardiographic studies on ischemic stroke patients, the prevalence of a PFO is higher in patients with a cryptogenic stroke. In a recent study of 61 patients, a PFO was found in $45 \%$ of those with cryptogenic stroke and in $23 \%$ of those with a stroke associated with large vessel atherosclerosis, lacunar ischemia, or cardiogenic embolism ${ }^{3}$. This discrepancy is larger in young patients than in the elderly ${ }^{14}$. Nevertheless, the role of echo-cardiography in the management of patients with acute stroke is not clear; recent recommendations on the management of acute stroke ${ }^{15,16}$ fail to consider echocardiography as an essential test in all patients.

Echocardiography is the investigation of choice when a cardiac source of embolism is suspected. However, debate persists about which patients with a stroke or thromboembolism requires imaging.

Transthoracic echocardiography combines real-time two-dimensional imaging of the heart and cardiac valves with information about velocity and direction of blood flow obtained by doppler and colour flow mapping. It is non-invasive, and a complete examination can be performed in most patients in less than $25 \mathrm{~min}$. So that it is of current issue whether use of echocardiography is useful to determine any occult cardiac abnormality in case of ischemic stroke. The goal of the current study was to determine the prevalence of heart disease that would have therapy implications (anticoagulation) in acute ischemic stroke patients without atria fibrillation.

Objectives: To find out prevalence of occult cardiac abnormality in ischemic stroke patients, through echocardiography. To find out the frequency of different type cardiac abnormality in ischaemic stroke.Age and sex ratio of cardiac abnormalities in stroke patients.

\section{Methods:}

It was a descriptive study conducted in Neurology unit, Chittagong Medical College hospital. Population was the patients presented primarily as ischaemic stroke in dept. of neurology, Chittagong medical college and hospital during the period from January 2007 to December 2007. All patients admitted in the Neuromedicine unit were included if they are with Ischaemic stroke. Patient were sent for Echocardiography after patient's condition becomes stable for at least 24 hours and GCS - ${ }^{3}$ 10.Echocardiography will be done in Cardiology department of $\mathrm{CMCH}$.Data were collected by direct interviewing the patient or there close attendants and examining the patients and collecting all information's and the results of relevant investigations will be noted in a data entry sheet for final analysis.

Sampling technique was purposive and I included number of patients available within the above mentioned time. All the patients presented as stroke which ischaemic, confirmed by CT scan of brain and GCS of the patient is ${ }^{3} 10$ and if patient is fit to bring to cardiology dept. for echocardiography was included in the study.

Exclusion criteria: a. Known cardiac abnormality. b. Known comorbid conditions that can cause stroke.(e.g. Vasculitis, Familial hypercholesterolemia, hyperhomocystinemia etc.)

Data Collection: The history and findings of physical examination including investigational findings will be recorded after informed consent of the patient or the patients guardian. All data will be collected in individual case record form (Annex). The necessary investigation results will be collected and recorded in an attached sheet. Collected data will be managed and analyzed using computer with 
statistical package SPSS. P value $<0.05$ was taken as minimum level of significance.

Observation and results: A total number of 265 patientswere examined. A total number of 350 patients were interviewed to obtain 265 cases. Among them, 85 patients were excluded from the study due to presence of Haemorrhagic stroke (55), Noncooperation (15), severe cardio-respiratory condition (5), deep coma (6), and death (4) of patients respectively. No control subject has not been taken as this study is to observe the presence of underlying cardiac abnormality among stroke patients who are not previously known as cardiac patient.
Table-I

Distribution of patient by Sex and Inhabitance

\begin{tabular}{lccccc}
\hline Sex & Total & Rural & $\%$ & Urban & $\%$ \\
\hline Male & 163 & 131 & 80.4 & 32 & 19.6 \\
Female & 102 & 84 & 82.4 & 18 & 17.6 \\
\hline Total & 265 & 215 & 81.13 & 50 & 18.87 \\
\hline
\end{tabular}

Table- 1 shows that maximum number of patients are from rural area $(81.1 \%)$ and smaller number are from Urban area(18.9\%).Male female ratio from urban and rural area are similar.

Table-II

Showing different Echocardiographic findings in different age group of patients.

\begin{tabular}{|c|c|c|c|c|c|c|}
\hline \multirow[t]{2}{*}{$\overline{S L}$} & \multirow[t]{2}{*}{ Echocardiography findings } & \multicolumn{5}{|c|}{ Age } \\
\hline & & $<30 y r s$ & $30-49 y r s$ & $>50-69 y r s$ & e"70yrs & total \\
\hline 1 & Cardiac arrythmia & 0 & 0 & 2 & 1 & 3 \\
\hline 2 & PFO & 0 & 0 & 0 & 0 & 0 \\
\hline 3 & Mitral stenosis & 2 & 0 & 1 & 0 & 3 \\
\hline 4 & Mitral regurgitation & 1 & 1 & 1 & 0 & 3 \\
\hline 5 & Aortic stenosis & 0 & 2 & 0 & 0 & 2 \\
\hline 6 & Aortic regurgitation & 0 & 0 & 1 & 0 & 1 \\
\hline 7 & Multiple valvular lesions & 2 & 2 & 0 & 0 & 4 \\
\hline 8 & Aortic valve calcifications & 0 & 0 & 2 & 1 & 3 \\
\hline 9 & LV hypertrophy & 0 & 1 & 7 & 3 & 11 \\
\hline 10 & LV dilatations & 0 & 0 & 2 & 0 & 2 \\
\hline 11 & Myocardial infarction & 0 & 0 & 2 & 1 & 3 \\
\hline 12 & Diastolic dysfunctions & 0 & 2 & 4 & 2 & 8 \\
\hline 13 & Intracardiac thrombus & 0 & 1 & 1 & 0 & 2 \\
\hline 14 & Mitral valve prolapse & 0 & 0 & 0 & 0 & 0 \\
\hline 15 & Left atrial dilatation & 0 & 0 & 2 & 0 & 2 \\
\hline \multirow[t]{3}{*}{16} & Normal findings & 15 & 24 & 145 & 34 & 218 \\
\hline & Cases of echocardiographic abnormalities & 5 & 9 & 25 & 8 & 47 \\
\hline & $\%$ of incedence of abnormalities & 25 & 27 & 15 & 19 & 18 \\
\hline
\end{tabular}


Table-III

Sex distribution of cases and findings.

\begin{tabular}{lcccc}
\hline Sex & No. of cases & $\%$ of total & No of Echo abnormality & \% of Echo abnormality \\
\hline Male & 163 & $61.5 \%$ & 36 & $22 \%$ \\
Female & 102 & $38.5 \%$ & 11 & $11 \%$ \\
\hline Total & 265 & $100 \%$ & 47 & $18 \%$ \\
\hline
\end{tabular}

Table-IV

Showing age group distribution of patient and findings.

\begin{tabular}{lccccc}
\hline Age group & $<30 \mathrm{yrs}$ & $30-49 \mathrm{yrs}$ & $>50-69 \mathrm{yrs}$ & $370 \mathrm{yrs}$ & Total \\
\hline Total patient & 20 & 33 & 170 & 42 & 265 \\
Abnormal cardiac findings & 05 & 09 & 25 & 08 & 47 \\
\% of abnormality & 25 & 27 & 15 & 19 & 18 \\
\hline
\end{tabular}

Table-V

Shows distribution of risk factors among cases

\begin{tabular}{lcccccc}
\hline Risk factors & Male & $\%$ & Female & $\%$ & Total & $\%$ \\
\hline Smoking & 117 & 72 & 11 & 11 & 128 & 48.3 \\
DM & 40 & 15.1 & 25 & 24.5 & 65 & 24.5 \\
Hypertension & 80 & 49 & 60 & 58.8 & 140 & 52.8 \\
H/O TIA & 6 & 3.68 & 2 & 1.96 & 8 & \\
H/O Taking OCP & & & 18 & 17.6 & 18 & 17.6 \\
H/OAlcohol & 4 & 1.5 & nil & & & 1.5 \\
\hline
\end{tabular}

Table-2: Showing prevalence of different type of cardiac abnormality in different age group of patients. Highest $\%$ of abnormality found in 30-49 yrs age group(27\%), followed by under $30 y$ rs age group(25\%). Overall prevalence is $18 \%$.

Table-3 showing distribution of sex and echocardiographic findings in different sex group.Here $61.5 \%$ of patients are male and $31.5 \%$ of patients are female.Abnormal echo findings found in $22 \%$ of male and $11 \%$ of female patients.

Table-IV showing maximum number of of patients(170) were of within 50-69 years of age .

Table- 5 shows percentages of different risk factors among different sex. Overall $48.3 \%$ were smoker, of them $72 \%$ of male and $11 \%$ of female were smoker.DM present in $24.5 \%$, HTN in $52.8 \%$.
Among female, $17.6 \%$ were taking OCP.Only 4 male patient was found Alcoholic.

\section{Discussion:}

This was a hospital based study and was carried out to see the prevalence of cardiac abnormality in patient of ischemic stroke. The study subjects were taken from the Department of Neurology, Chittagong Medical College and Hospital, Chittagong. During the study period, from January 2007 to December 2007. 265 patients, diagnosed as ischemic stroke clinically and confirmed by CT scan of head, were evaluated. In the study, majority $(64 \%)$ of the subjects were in between $50-69$ years of age. In this study the $61.50 \%$ were male and $38.50 \%$ were female. The male to female ratio was 1.6:1. Male involvement was higher than females. This difference may be due to the sociocultural stigma prevailed in our country. Females are not generally brought to hospital.Majority of study 
subject were rural $(81 \%)$ inhabitance. This may be due to the fact that majority of the urban patient treated in Private Clinic and Doctor's chamber. This study showed majority of study subject were retired person $(19.8 \%)$, businessman(19.8\%) and housewife(19.8\%).In the present study showed that $72 \%$ of male and $11 \%$ of female stroke patients were smoker . .In this study $10 \%$ stroke patients had family history of stroke. It is lower then the some previous study parameter( $18.50 \%)$. This may be due to increase awareness of the population about prevention of stroke and increase awareness of diabetes mellitus and hypertension. In this study, history of OCP present in $17.5 \%$ of female patients. It is higher then the some previous study. This difference may be due to good impact of family planning program in our society.

In this study, Table- 4 Shows that $18 \%$ of patients who are not previously bearing any known cardiac abnormality, found to have some cardiac abnormality in transthoracic echocardiography. Recognised textbook and journals showed that around $20 \%$ of patient of ischemic stroke patient bears underlying abnormality in heart ${ }^{15}$. In this study frequency of cardiac abnormality found slightly lower then recognized text, probably due to lack of facility to do the TEE, which can diagnose trivial abnormalities which has lack of sensitivity in TTE.

In this study there are different frequency of cardiac abnormality in different age group.Most structural cardiac abnormality found in under 30 age group.In this group $25 \%$ cases showed some abnormal findings. In this group all the cardiac abnormalities found are valvular abnormality, which are mitral stenosis(2), mitral regurgitation(1), multiple valvular disease(2). These structural lesions are probable culprit in many case of young stroke patients.

Other age group showed abnormality in $27 \%$ cases in 30-49yrs age group which is the highest frequency , 15\% abnormal findings in 50-69 yrs age group which is lowest frequency and 19\% echocardiographic findings found in over $70 \mathrm{yrs}$ age group.

In this study structural abnormality are frequent in $<50$ age group and functional cardiac abnormality are more in $>50$ age group of patients. Functional abnormality like diastolic dysfunctions, Left ventricular hypertrophy or dilatation are more common among over 50 years aged patients.

In this study most frequent abnormality are found LVH (11)(23\%) which is consistent with previous similar study ${ }^{17}$. Most of the case of LVH are in patient of over 50 years of age. This is probably due to long standing uncontrolled hypertension, as in our rural area most of the hypertensive patients are either remain untreated or maltreated.

Previous study and literature showed that a significant number of patients with $\mathrm{PFO}^{17}$, but in this study there were no case of PFO was found. Patent foramen ovale (PFO), a persistence of an embryonic defect in the interatrial septum, is present in up to $27 \%$ of the general population ${ }^{16}$. Thus, detection of a PFO during evaluation of a patient with a stroke is not surprising, and the frequency of PFO detection in these patients can be as high as $40-45 \%$. This frequency of detection is especially high among people without any other obvious explanation for the stroke. Concluded from a metaanalysis of several studies that the relative risk of stroke compared to non-stroke controls increased by a factor of 1.83 if a PFO was present. We found no case of PFO probably due to lack of sensitivity of TTE in detecting PFO.If TEE could be done, than PFO could be identified.

Diastolic dysfunction found second commonest finding in this study. $17 \%$ of the abnormal findings found to have diastolic dysfunctions. Most of the cases of diastolic dysfunctions are found in over 50 years of age.Cardiac arrhythmia found in $3(6.38 \%)$ cases. All are over 50 years of age.

Valvular abnormality found in $16(34 \%)$ cases, among them most(62.5\%) are of under 50 years age group. Aortic valve calcification found in 3 cases, all are aged over 50 years.

In conclusion of this study it can be said that significant number of patient of cryptogenic ischemic Ischemic stroke patient shows cardiac abnormality in echocardiography, which may be the contributor of the occurrence of stroke.

\section{Conclusion:}

Stroke is the $2^{\text {nd }}$ leading cause of mortality in the world. Echocardiography may provide important information on the cause of ischemic stroke. Taking into account a low rate of findings with direct impact on evidence-based therapeutic strategies, routine use of echocardiography is not warranted in all patients with stroke. In patients younger than 50 years, echocardiography has higher diagnostic yield and should routinely be performed. Among older patients, routine echocardiography results in a high 
rate of non-specific findings. To avoid unnecessary hazard and costs associated with redundant diagnostic procedures and unproven therapies, echocardiography can be done selectively in these patients, targeted at specific clinical problems.

\section{References:}

1. Bogousslavsky J, Kaste M, Olsen TS, Hacke W, Orgogozo JM. Risk factors and stroke prevention. Cerebrovasc Dis. 2000;10(suppl 3):12-21

2. Qureshi Al, Tuhrim S, Broderick JP, Batjer HH, Hondo H, Hanley DF. Spontaneous intracerebral hemorrhage. N Engl J Med. 2001;344: 1450-1460.

3. European Stroke Initiative. Stroke prevention by the practitioner. Cerebrovasc Dis. 1999;9 (suppl 4):1-61.

4. Adams HP Jr, Bendixen BH, Kappelle LJ, Biller J, Love BB, Gordon DL, Marsh EE III. Classification of subtype of acute ischemic stroke. Definitions for use in a multicenter clinical trial. TOAST. Trial of Org 10172 in Acute Stroke Treatment. Stroke. 1993;24(1):35-41.

5. Semple PF, Sacco RL. An Atlas of Stroke. 2nd ed. London, UK: The Parthenon Publishing Group; 1999:24.

6. Kistler JP. The risk of embolic stroke: another piece of the puzzle. N Engl J Med. 1994;331(22):1517-1519.

7. Amarenco P, Cohen A, Tzourio C, Bertrand B, Hommel M, Besson G, Chauvel C, Touboul PJ, Bousser MG. Atherosclerotic disease of the aortic arch and the risk of ischemic stroke. N Engl J Med. 1994;331: 1474-1479.

8. Majerus PW, Broze GJ, Miletich JP, Tollejseu DM. Anticoagulant, thrombolytic and antiplatelet drugs. In: Hardman JG, Limbird LE, Molinoff PB, Ruddon RW, Gildman AG, eds. Goodman and Gilman's the Pharmacological Basis of Therapeutics. 9th ed. New York: McGraw-Hill; 1996:1341-1359.

9. Mohr JP, Thompson JL, Lazar RM, Levin B, Sacco RL, Furie KL, Kistler JP, Albers GW, Pettigrew LC, Adams HP Jr, Jackson CM, Pullicino P; Warfarin-Aspirin Recurrent Stroke
Study Group. A comparison of warfarin and aspirin for the prevention of recurrent ischemic stroke. N Engl J Med. 2001;345:1444-1451.

10. Powers JW. Oral anticoagulant therapy for the prevention of stroke. N Engl J Med. 2001;345(20):1493-1495.

11. Albers GW, Amarenco P, Easton JD, Sacco RL, Teal P. Antithrombotic and thrombolytic therapy for ischemic stroke. Chest 2001;119: 300S-320S.

12. Davidson's principles and practice of medicine. $20^{\text {th }}$ edition. London, UK: Churchill Livingstone; 1202.

13. Ralph L. Sacco, Robert Adams, Greg Albers, Mark J. Alberts, Oscar Benavente, et al. Guidelines for Prevention of Stroke in Patients With Ischemic Stroke or Transient Ischemic Attack: A Statement for Healthcare Professionals From the American Heart Association/American Stroke Association Council on Stroke: Co-Sponsored by the Council on Cardiovascular Radiology and Intervention: The American Academy of Neurology affirms the value of this guideline. Stroke. 2006; 37:577-617.

14. Meier B, Lock JE. Contemporary Management of Patent Foramen Ovale Circulation. 2003; 107(1):5-9.

15. Harold P. Adams, Jr, Chair; Robert J. Adams, Thomas Brott, Gregory J. del Zoppo, Anthony Furlan, et al. Guidelines for the early management of patients with ischemic stroke: a scientific statement from the Stroke Council of the American Stroke Association. Stroke. 2003;34(4):1056-1083.

16. The European Stroke Initiative Executive Committee and the EUSI Writing Committee. European Stroke Initiative Recommendations for Stroke Management: update 2003. Cerebrovasc Dis. 2003; 16: 311-337.

17. Thomas W, Micha M, Ramin A, Ina B, Robert B, Hans R, et al. Should Routine Echocardiography Be Performed in All Patients With Stroke? Journal of Stroke and Cerebrovascular Diseases. 2007, 16(1):1-7. 